\title{
Modeling and experimental verification of infusion speed of liquids in photonic crystal
} fibers

Sørensen, Thorkild; Noordegraaf, Danny; Nielsen, Kristian; Bjarklev, Anders Overgaard; Hansen, Theis Peter

Publication date:

2005

Document Version

Publisher's PDF, also known as Version of record

Link back to DTU Orbit

Citation $(A P A)$ :

Sørensen, T., Noordegraaf, D., Nielsen, K., Bjarklev, A. O., \& Hansen, T. P. (2005). Modeling and experimental verification of infusion speed of liquids in photonic crystal fibers. Poster session presented at 2005 Optical Fiber Communication Conference and Exhibition, Anaheim, CA, United States.

\section{General rights}

Copyright and moral rights for the publications made accessible in the public portal are retained by the authors and/or other copyright owners and it is a condition of accessing publications that users recognise and abide by the legal requirements associated with these rights.

- Users may download and print one copy of any publication from the public portal for the purpose of private study or research.

- You may not further distribute the material or use it for any profit-making activity or commercial gain

- You may freely distribute the URL identifying the publication in the public portal 


\title{
Modeling and experimental verification of infusion speed of liquids in photonic crystal fibers
}

\author{
T. Sorensen, D. Noordegraaf, K. Nielsen, and A. Bjarklev \\ Research Center COM, Technical University of Denmark, Building 345V, DK-2800 Kgs. Lyngby, Dennark \\ thors@com.dtu.dk \\ T. P. Hansen \\ Cystai Fibre A/S, BIokken 84, DK-3460 Birkerød, Denmark, and also Research Center COM, DTU, Denmark
}

\begin{abstract}
A theoretical method for predicting infusion time of liquids in microcapillaries is formulated. Through a microscopical, a fluorescent, and, finally, through a reflectometric measurement method, the model is successfully verified in real photonic crystal fibers. (c) 2005 Optical Society of America.

OCIS codes: (060.2400) Fiber properties; (230.3990) Microstructured devices; (060.2370) Fiber optics sensors.
\end{abstract}

\section{Introduction}

Since the first presentation of photonic crystal fibers (PCFs) in 1996 [1], research within this class of fiber optics has attracted a vast amount of scientific interest. Probably one of their most appealing features is the large degree of tunability that may be achieved by arranging the holes of the photonic crystal cladding. Recently, microstructured specialty fiber devices have been presented [2] whose realization had not been possible by standard fiber technology alone, simply because the limits of single-material manufacture have been broken. For these hybrid-material fibers, as well as their siblings, the PCF-based sensors [3,4], however, a large problem often occurs, namely the question of how difficult will it be to infuse a desired medium into the fiber. Here, a model is presented, which enables an estimate to be made on the magnitude of the required effort, the amount of time that it will take, and the model is verified through three different experiments.

\section{Theoretical considerations on liquid infusion inside a PCF capillary}

The equation that determines the capillary force inside a circular tube is given by the expression [5]:

$$
F_{\text {capillary }}=2 \pi a \sigma \cos (\theta)
$$

in which $a$ is the hole radius, $\sigma$ is the surface tension, and $\theta$ is the contact angle, see Fig. 1, left. For the case of $\mathrm{H}_{2} \mathrm{O}$ and $\mathrm{SiO}_{2}$, the contact angle is 0 . In the interval from 0 to 100 Celsius, the surface tension can be approximated by the expression $\sigma(\mathrm{T})=-2.75 \times 10^{-7} \times \mathrm{T}^{2}-1.4 \times 10^{-4} \times \mathrm{T}+0.0756[\mathrm{~N} / \mathrm{m}]$. It is noteworthy that almost any possible flow of a liquid in a PCF capillary, is laminar. After a modification of existing microfluidic models, intended for use in rectangular channels $[6,7]$, a differential equation for the filling length, $L$, of a circular tube, as a function of time, $t$, is found to be:

$$
\frac{d^{2}}{d t^{2}}\left(L^{2}\right)+B \frac{d}{d t}\left(L^{2}\right)+2 g L=A
$$

where

$$
A=\frac{\pi \sigma \cos (\theta)+2 \Delta P \pi a}{\rho a} \text { and } B=\frac{8 \mu}{\rho a^{2}}
$$

Here, $\mu$ is the dynamic viscosity of the liquid, $\rho$ is the density, and $\Delta P$ is an applied overhead pressure. In the interval from 10 to 30 Celsius, this viscosity can be approximated by the expression $\mu(\mathrm{T})=5 \times 10^{-7} \times \mathrm{T}^{2}$ $4.55 \times 10^{-5} \times \mathrm{T}+1.713 \times 10^{-3}\left[\mathrm{Ns} / \mathrm{m}^{2}\right]$. Equation (2) is solved with respect to the filling length, $\mathrm{L}$, and for this purpose, a Matlab ${ }^{\otimes}$ program was developed. An important assumption of this model is that we are dealing with Poiseuille flow [5]. This means that there is no slip between the silica wall and the nearest molecules of the liquid, and that the liquid is Newtonian. Plots of the time necessary for the filling of various lengths of fiber are shown in Fig. 1, right. 


\section{OME3}

For hole radii below 5 microns, gravity can be neglected in the case of water, or most aqueous solutions, inside a silica fiber.
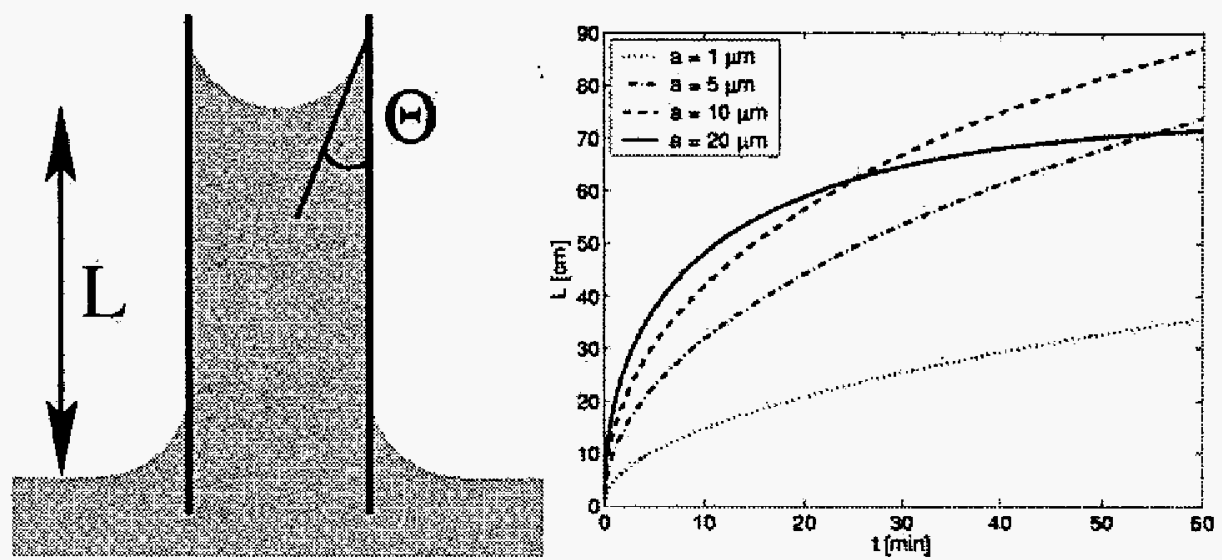

Fig. 1. Left: schematics of the rise of a fluid in a capillary, as well as the contact angle, $\boldsymbol{\theta}$. Right: Filled capillary length v. time for capillaries of radii of $1,5,10$, and 20 microns, respectively.

\section{Experimental results on liquids inside photonic crystal fibers}

The first principle of verification that was applied, was to place the end facet of a specific fiber length near a microscope and measure the time of filling of the cladding air holes. In Fig. 2, images of this are shown.
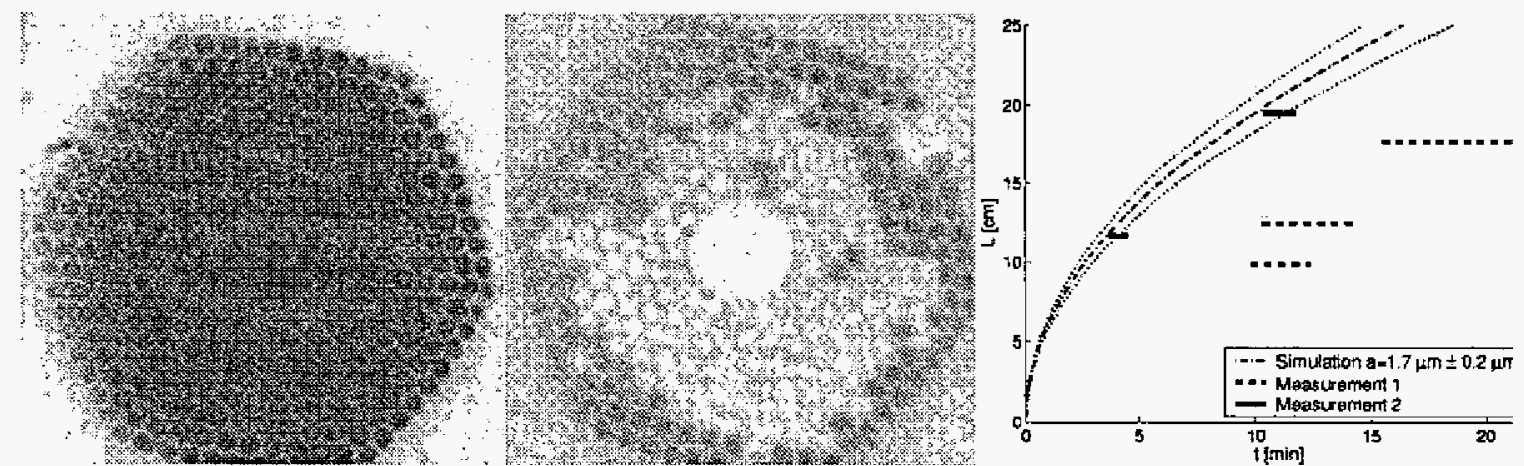

Fig. 2. Left: End facet of empty air-guiding PCF, middle: the same fiber when water has reached the end facet. Some holes are not filled, this is expected to be due to impurities and dust. Right: Correspondence between model and experiment. Measurement 1 is when the illumination system of the microscope heats the fiber, and Measurement 2 is with a shielded fiber, so evaporation is avoided. Air-hole radius is 1.7 microns.

In the process of this experiment, an interesting effect was discovered. The illumination system of the microscope did in fact heat the fluid to evaporation, Fig. 2, right (dashed lines) and, in error, a much longer filling time was observed. After properly shielding of the fiber under test, a measurement time (solid lines) that agrees well with the simulation results (dash-dot lines) was recorded. The second examination of the model was conducted by adding a fluorescent agent (cy3 dye that absorbs at $550 \mathrm{~nm}$ and emits at $570 \mathrm{~nm}$ ) [4] to the infusion liquid, whereafter the fiber was examined from the side with a microscope, that is fitted with filters, only to see light at $570 \mathrm{~nm}$. This experiment was made at ambient pressure, as well as with an overhead pressure of $1.45 \mathrm{bar}$, and through repeated measurements the data coincided well with the predictions of the model. This method has the advantage that up to four measurement points were obtainable with each piece of fiber. 


\section{OME3}

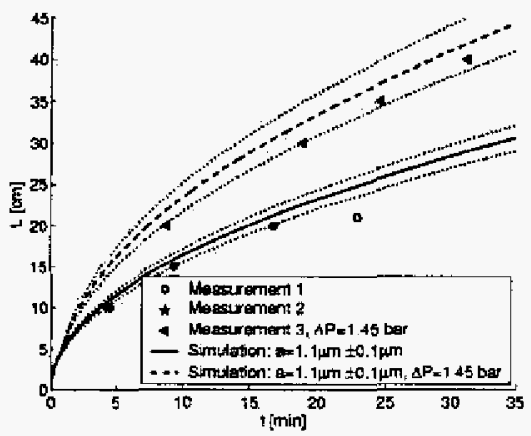

Fig. 3. Calculated infusion speed at ambient pressure (solid) and with an overhead pressure of 1.45 bar (dashed). Measured points, except one, agree well with theoretical predictions. Air-hole radius was 1.1 microns.

The idea behind the third principle of verification was to use a HP8504B precision reflectometer to observe reflections from the air/water interface inside the PCF structure, from points at which the water surface could be measured at a given time, thus making it possible to use only one piece of fiber per experiment, as in the aforementioned test principle, but now with up to ten measurements per fiber piece.
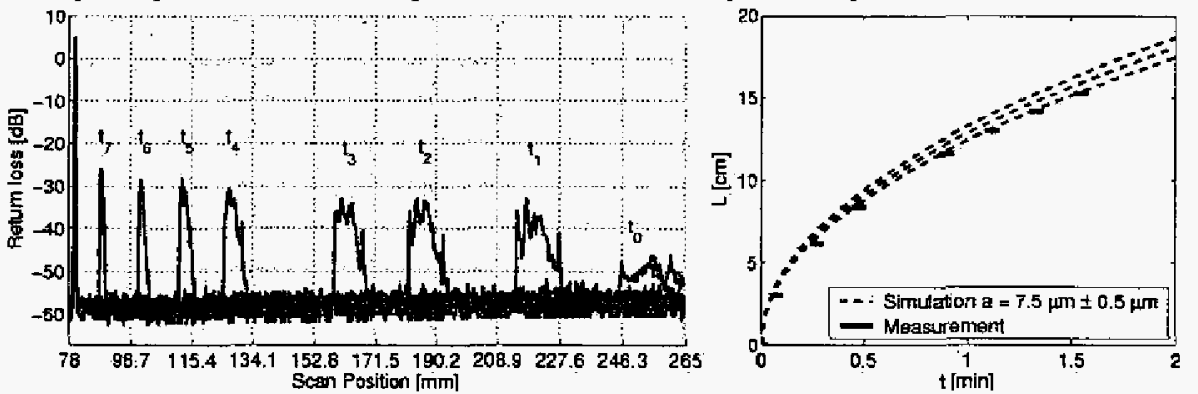

Fig. 4. Measurements with a HP8504B precision reflectometer. Lef: Points, at which the reflection from the air/water interface gives a signal. Right: Correspondence between theoretical model (dashed lines) and measurements (solid lines) Air-hole radius was 7.5 microns.

Within the estimated uncertainty, the third experimen! proved successful. Nonetheless, it is seen that, as well as for the other experiments, the model predicts a slightly shorter infusion time than experimentally observed. This may be due to the fact that the assumption of Poiseuille flow could be close to violation, since there is acceleration, at least to some degree, at the regions near the beginning and near the end of the capillary [8].

\section{Conclusions}

A model for the speed of infusion of liquids into a photonic crystal fiber has been presented, and furthermore it has been verified through three different experiments. First, a simple microscope view at the end facet was used to determine the time, at which a given length of the fiber was filled, second, a method that involved adding a fluorescent agent allowed for examination from the side, and finally, a reflectometric method, allowing for a distributed series of measurements was done. The measurements agree well with the predicted data.

\section{References}

[1] J. C. Knight, T. A. Birks, P. St. J. Russell, D. M. Afkin, "All-silica single-mode optical fiber with photonic crystal cladding" Opt. Lett. 21, 1547-1549 (1996).

[2] B. J. Eggleton. C. Kerbage, P. Westbrook, R. S. Windeler, and A. Hale, "Microstructured optical fiber devices", Opt. Express 9, 13, 698-713 (2001).

[3] T. Ritari, J. Tuominen, H. Ludvigsen, J. C. Petersen, T. Sørensen, T. P. Hansen, H. R. Simonsen, " Gas sensing using air-guiding photonic bandgap fibers". Opt. Express 12, 4080-4087 (2004).

[4] J. B. Jensen, L. H. Pedersen, L. H. Pedersen, P. E. Hoiby, L. B. Nielsen, T. P. Hansen, J. R. Folkenberg, J. Riishede, D. Noordegraaf, K. Nielsen, A. Carlsen, A. Bjarklev, "Photonic crystal fiber based evanescent-wave sensor for detection of biomolecules in aqueous solutions", Opt. Lett. 29, 1974-1976 (2004).

[5] B. S. Massey, "Mechanics of fluids", (Chapman and Hall 1991).

[6] J.Zeng. "On modeling of capillary filling", hitt://www.coventor.com/microfluidics/papers/ (Coventor Inc. 2004).

[7] B. V. Zhmud, F. Tiberg, and K. Hallstenson, "Dynamics of capillary rise", Journ. Colloid and Interface Science 228, 263-269 Academic Press $(2000)$.

[8] W. Huang, R. S. Bhullar, Y. C. Fung. "The surface-tension-driven flow of blood from a droplet into a capillary tube", Journ. Biomech. Eng. $123,446-454,2001$. 